\title{
A 53-year-old woman with abdominal pain and fullness
}
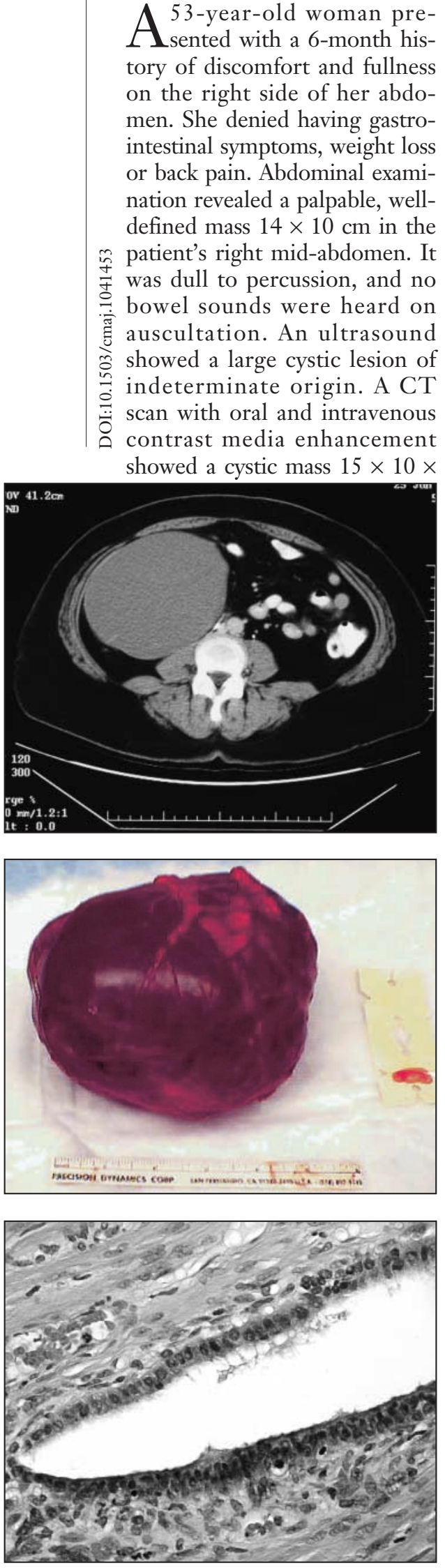

$13 \mathrm{~cm}$ that was causing mild hydronephrosis and significant anterior displacement of the bowel loops (Fig. 1). A barium test of the gastrointestinal tract and intravenous pyelography confirmed the CT scan findings and revealed medial displacement of the duodenum and right upper ureter.

The mass was excised easily through a transverse extraperitoneal approach. It did not adhere to the surrounding organs and was supplied by a few small vessels. The excised cyst had a smooth chocolate-coloured surface, measured $16 \times 13 \times 12 \mathrm{~cm}$ and weighed $1160 \mathrm{~g}$ (Fig. 2). Its interior contained old chocolatecoloured blood. Microscopic examination revealed that the cyst was lined by flat nonpapillary benign epithelium that resembled mesothelial, focally ciliated, tuboendometrioid epithelium (Fig. 3). The results of immunohistochemical analysis were positive for cytokeratin and for estrogen and progesterone receptors, but negative for calretinin. The histologic features and immunohistochemical analysis supported the diagnosis of a benign müllerian duct cyst.

Cystic lesions in the retroperitoneal space are uncommon. The majority are of lymphatic or enteric origin or are cystic neoplasms. Müllerian duct cysts are extremely rare in the retroperitoneum. ${ }^{1,2}$ In early embryonic life the gonadal system develops from 2 different ductal structures, known as müllerian and wolffian ducts. If the gonads develop into ovaries, the wolffian duct system atrophies, allowing the müllerian system to develop, with 1 duct on each side. Eventually the 2 ducts fuse to form the uterus, fallopian tubes and the upper part of the vagina. In the male the atrophied müllerian ducts remain as the prostatic utricle. ${ }^{3,4}$ If a small part of the embryonic duct sepa- rates as an anomaly and fails to regress, it can continue to grow and present as a cystic mass in infancy or adult life. Remnants are usually found in females in the broad ligaments and in males in the retrovesical space. ${ }^{3}$

The clinical presentation in all of the reported cases was no different from that of other lesions in the retroperitoneum. Vague abdominal pain, with or without back pain, and a palpable mass are the main presenting symptoms. Large lesions grow anteriorly in the path of least resistance and displace the intestine, and thus can mimic mesenteric cysts. Medial deviation of the ureter is another common finding. The diagnosis is based on the histologic finding of ciliated columnar and endometrioid epithelium similar to the lining of the fallopian tubes and the endometrium. When it is difficult to positively identify the type of epithelium, immunohistochemical analysis is essential to confirm the origin of the cells. ${ }^{1}$ As in our case, the cysts in all of the reported cases were benign, and, although they were close to various vital retroperitoneal structures, surgical excision was easy.

Mihir Ray

Bireswar Bose

Department of Surgery

Fort Saskatchewan Hospital

Fort Saskatchewan, Alta.

Louis Honoré

Department of Pathology

University of Alberta

Edmonton, Alta.

\section{References}

1. Konishi E, Nakashima Y, Iwasaki T. Immunohistochemical analysis of retroperitoneal Mullerian cyst. Hum Patbol 2003;34:194-7.

2. Lee J, Song SY, Park CS. Mullerian cysts of the mesentery and retroperitoneum: a case report and literature review. Pathol Int 1998;48:902-6.

3. Skandalakis JE, Gray SW. Embryology for surgeons. 2nd ed. Baltimore: William and Wilkins; 1994. p. 823.

4. Larson WJ. Human embryology. 3rd ed. New York: Churchill Livingston; 2001. p. 282. 